\title{
Association of SIRT-1 Gene Polymorphism and Vitamin D Level in Egyptian Patients With Rheumatoid Arthritis
}

\author{
Dina Sabry a, f, Shereen Rashad Kaddafy ${ }^{\mathrm{b}}$, Ahmed Ali Abdelaziz ${ }^{\mathrm{c}}$, Abdelfattah Kasem Nassarc \\ Mohamed Moneer Rayan ${ }^{c}$, Sadek Mostafa Sadek ${ }^{\mathrm{d}}$, \\ Amany A Abou-Elalla ${ }^{\mathrm{e}}$
}

\begin{abstract}
Background: We investigated SIRT-1 genetic variant and its association with vitamin D level in Egyptian patients with rheumatoid arthritis (RA).

Methods: Seventy Egyptian subjects were enrolled in our study and divided into two groups: RA group $(n=50$ patients $)$ and healthy control group ( $\mathrm{n}=20$ subjects). Five milliliter blood sample was withdrawn from each subject followed by laboratory investigation and DNA extraction for SIRT-1 gene polymorphism assessment (rs7895833 A $>\mathrm{G}$, rs7069102 $\mathrm{C}>\mathrm{G}$ and rs2273773 $\mathrm{C}>\mathrm{T}$ ) and vitamin $\mathrm{D}$ level expression.

Results: There was statistically significant difference between rheumatoid cases and controls with regard to vitamin D level with $88 \%$ of cases showing insufficient vitamin D versus all controls showing sufficient level. SIRT-1 different SNPs rs2273773, rs7895833and rs7069102 genotype frequencies were statistically significant in RA compared to control group ( $\mathrm{P}=0.001)$. There was no statistically significant difference between different genotypes of rs2273773, rs7895833 and rs7069102 with regard to vitamin D level.
\end{abstract}

Conclusion: We concluded that there is a strong association between SIRT-1 polymorphism genotyping and RA. Vitamin D level was insufficient in Egyptian patients with RA.

Keywords: SIRT-1 polymorphism; Vitamin D; Rheumatoid arthritis; Egypt

Manuscript submitted May 15, 2017, accepted June 16, 2017

${ }^{a}$ Medical Biochemistry and Molecular Biology, Faculty of Medicine, Cairo University, Cairo, Egypt

${ }^{b}$ Medical Biochemistry and Molecular Biology, Faculty of Medicine, Fayoum University, Al Fayoum, Egypt

'Department of Rheumatology and Rehabilitation, Faculty of Medicine, AlAzhar University, Cairo, Egypt

dDepartment of internal medicine, Faculty of Medicine, Al-Azhar University, Cairo, Egypt

${ }^{\mathrm{e} T e c h n o l o g y}$ of Medical Laboratory, Faculty of Applied Medical Sciences, Misr University for Science and Technology, 6th of October City, Egypt

${ }^{f}$ Corresponding Author: Dina Sabry, Medical Biochemistry and Molecular Bi-

ology, Faculty of Medicine, Cairo University, Cairo, Egypt.

Email: dinasabry@kasralainy.edu.eg

doi: https://doi.org/10.14740/jocmr3067e

\section{Introduction}

Rheumatoid arthritis (RA) is an autoimmune disease, resulting in a chronic, systemic inflammatory disorder [1]. It is a disease affecting joint cartilage and bone with synovial inflammation and infiltration of inflammatory immune cells [2].

Vitamin D deficiency was shown to have a role in increased levels of proinflammatory cytokines and it plays a very important role in the reduction of inflammation, by suppression of prostaglandin (PG) action, inhibition of p38 stress kinase signaling, and the production of proinflammatory cytokines and inhibition of nuclear factor- $\mathrm{kB}(\mathrm{NF}-\mathrm{\kappa} B)$ signaling [3].

The SIRT-1 gene is located on the 10q21.3 chromosome [4]. SIRTs are a conserved family of NAD + dependent histone deacetylases (HDACs) and mono-ADP-ribosyltransferases that target histones, transcription factors and coregulators to adapt gene expression to the cellular energy state [5]. HDACs are enzymes inhibiting gene expression by reversing acetylation of histone proteins. In mammals, seven sirtuin genes, SIRT-1 to SIRT-7, have been identified. Among them, SIRT-1 is best characterized so far. It has been shown that it regulates transcription factors such as members of the forkhead transcription factor FOXO family [6], p53 [7], NF-kB [8], the DNA repair factor $\mathrm{Ku} 70$ [9], and the transcriptional coactivator p300 [10].

SIRT-1 is found in many tissues such as pancreas, liver, skeletal muscle, brain and adipose tissue. It plays a crucial role in various human diseases such as cardiovascular diseases, inflammation, aging, neurodegenerative disease, non-alcoholic fatty liver disease (NAFLD), amyotrophic lateral sclerosis (ALS), and even cancers [11]. It has been reported that it is a potential therapy for NAFLD [12], ALS [13], kidney disease [14], and pulmonary disease [15].

We, therefore, conducted the SIRT-1 gene polymorphism (rs7895833 A $>\mathrm{G}$, rs $7069102 \mathrm{C}>\mathrm{G}$ and $\mathrm{rs} 2273773 \mathrm{C}>\mathrm{T}$ ) in the present study to investigate SIRT-1 genetic variants and its association with vitamin D levels in Egyptian patients with RA.

\section{Materials and Methods}

\section{Subjects}

The present study included 70 Egyptian subjects who were di- 
Table 1. Demographic Characteristics and Routine Investigations in Different Study Groups

\begin{tabular}{|c|c|c|c|}
\hline Variables & Rheumatoid cases $(n=50)$, mean \pm SD & Controls $(n=20)$, mean \pm SD & P-value \\
\hline \multicolumn{4}{|l|}{ Sex } \\
\hline Males & $38(76 \%)$ & $9(45 \%)$ & 0.023 \\
\hline Age (years) & $40.1 \pm 11.5$ & $43.3 \pm 9.8$ & 0.289 \\
\hline \multicolumn{4}{|l|}{ Complete blood count } \\
\hline $\operatorname{TLC}(10 / \mathrm{mm})$ & $6.6 \pm 2$ & $5.7 \pm 0.98$ & 0.047 \\
\hline PLT (10/mm) & $272.9 \pm 94.7$ & $239.1 \pm 68.6$ & 0.150 \\
\hline \multicolumn{4}{|l|}{ Liver function } \\
\hline $\operatorname{ALT}(\mathrm{IU} / \mathrm{L})$ & $44.6 \pm 13.6$ & $32.5 \pm 5.7$ & 0.000 \\
\hline Albumin $(\mathrm{g} / \mathrm{dL})$ & $4.1 \pm 0.48$ & $4.3 \pm 0.41$ & 0.058 \\
\hline \multicolumn{4}{|l|}{ Other investigations } \\
\hline Alkaline phosphatase (IU/L) & $67.2 \pm 26$ & $71.4 \pm 23$ & 0.536 \\
\hline Creatinine $(\mathrm{mg} / \mathrm{dL})$ & $0.91 \pm 0.29$ & $0.95 \pm 0.18$ & 0.02 \\
\hline $\mathrm{CRP}(\mathrm{mg} / \mathrm{L})$ & $0.24 \pm 0.13$ & $0.23 \pm 0.09$ & 0.707 \\
\hline INR & $1.07 \pm 0.10$ & $1.12 \pm 0.13$ & 0.143 \\
\hline Anti-CCP (U/ML) & $61.7 \pm 26$ & $6.9 \pm 4.5$ & 0.000 \\
\hline TSH (mIU/L) & $1.7 \pm 0.99$ & $1.7 \pm 0.77$ & 0.799 \\
\hline $\operatorname{AFP}(\mathrm{ng} / \mathrm{mL})$ & $2.9 \pm 2.1$ & $1.7 \pm 0$ & 0.012 \\
\hline
\end{tabular}

Independent $t$-test: Pearson $\mathrm{X}^{2}$ (exact). SD: standard deviation.

vided into two groups: RA group ( $\mathrm{n}=50$ patients) and healthy control group ( $\mathrm{n}=20$ subjects).

RA group included 38 men and 12 women with a mean age of $40.1 \pm 11.5$ years. Patients were clinically diagnosed by physical examination and laboratory investigations at the Faculty of Medicine, Al-Azhar and Cairo Universities. In addition, the control group included nine men and 11 women with a mean age of $43.3 \pm 9.8$ years. They were recruited from healthy subjects admitted to the same hospital.

Written informed consent was obtained from all subjects enrolled in the study. Approval for this study was not required in accordance with the policy of our institution.

\section{Biochemical investigations}

Blood samples of all subjects were centrifuged for $5 \mathrm{~min}$ at $4{ }^{\circ} \mathrm{C}$, followed by the removal of plasma and then stored at $-20{ }^{\circ} \mathrm{C}$. The following biochemical parameters were determined in both the control and RA groups by standard laboratory methods in the Faculty of Medicine, Cairo University: complete blood picture, total bilirubin, direct bilirubin, alanine aminotransferase (ALT), aspartate aminotransferase (AST), albumin, urea, creatinine, international normalized ratio (INR), and AFP. Whole blood samples of all subjects were analyzed for the genotypes of SIRT-1 and plasma for vitamin D level expression.

\section{DNA isolation}

The genomic DNA was extracted from whole peripheral blood sample using QIAamp DNA blood mini-kit extraction kit (Qiagen, Hilden, Germany) following the manufacturer's instructions.

All DNA samples were quantitated using the Nano Drop ${ }^{\circledR}$ 1000 spectrophotometer (Nanodrop Technologies, Inc., Wilmington, USA).

\section{SIRT-1 genotyping}

Genotyping was determined using real-time PCR (StepOne, Applied Biosystems, Foster City, USA). SIRT-1 SNPs includ- 
Table 2. ANA Titer and Vitamin D Levels in Study Groups

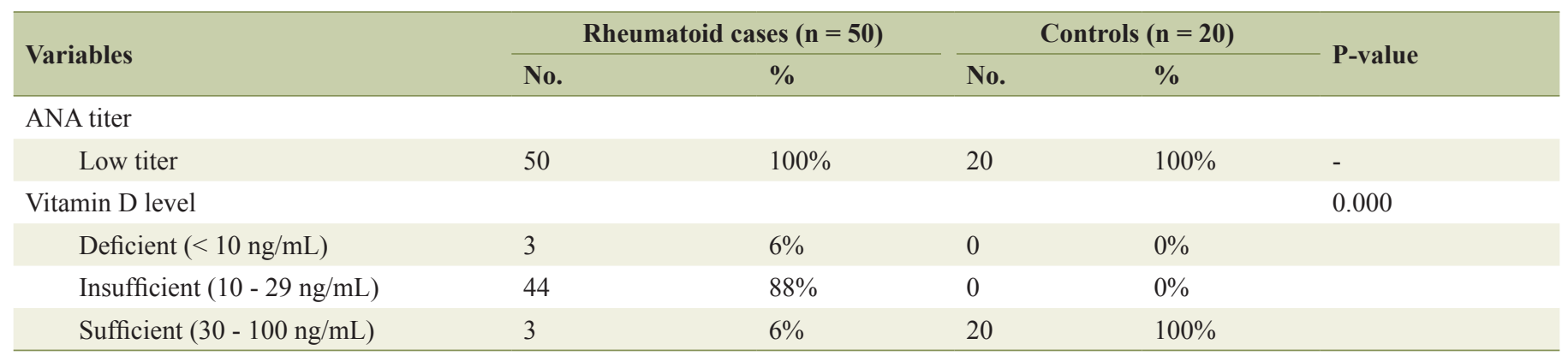

ing rs7895833 $\mathrm{A}>\mathrm{G}$ in the promoter region, rs7069102 $\mathrm{C}>\mathrm{G}$ in intron 4 and rs2273773 $\mathrm{C}>\mathrm{T}$ in exon 5 (Cat No. 4351379) were analyzed in the extracted DNA by using specific primers and Taqman FAM and VIC probes (Taqman SNP genotyping assays, Applied Biosystems, Foster City, CA). The 25 $\mu \mathrm{L}$ PCR mixture included $20 \mathrm{ng}$ of whole blood genomic extracted DNA and the following reagents: $0.5 \mu \mathrm{L}$ FAM and VIC probes and primers (Taqman SNP genotyping assays), $12.5 \mu \mathrm{L}$ Taqman universal master mix II No UNG (Cat No. 4440040) and DNase free water. The thermal cycling profile was $10 \mathrm{~min}$ at $95{ }^{\circ} \mathrm{C}$ for enzyme activation followed by 40 cycles of $15 \mathrm{~s}$ DNA denaturation at $95^{\circ} \mathrm{C}, 20 \mathrm{~s}$ primers and probes annealing at $55^{\circ} \mathrm{C}$, and $30 \mathrm{~s}$ at $72{ }^{\circ} \mathrm{C}$ for the amplification step. The genotyping was analyzed with StepOne Applied Biosystem version 2.1 soft ware analysis.

\section{Vitamin D serum level assessment}

Vitamin D plasma level was detected by ELISA 25-OH vitamin D kit according to instructions of manufactures (DRG, international Inc., USA). The data are expressed as ng/mL. Grading of vitamin D levels was done as follows: $\geq 30 \mathrm{ng} / \mathrm{mL}$ (normal); 10 - $30 \mathrm{ng} / \mathrm{mL}$ (insufficiency); $\leq 10 \mathrm{ng} / \mathrm{mL}$ (deficiency).

\section{Statistical analysis}

Data were collected and coded to facilitate data manipulation and double entered into Microsoft Access and data analysis was performed using SPSS software version 18 in windows 7. Simple descriptive analysis in the form of numbers and percentages for qualitative data, and arithmetic means as central tendency measurement, standard deviations as measure of dispersion for quantitative parametric data, and inferential statistic test: Student's $t$-test used to compare measures of two independent groups of quantitative data were conducted. P value $\leq$ 0.05 was considered the cut-off value for significance.

\section{Results}

Fifty patients suffering from RA were enrolled in this study together with 20 subjects as controls. Among the 50 patients, 38 $(76 \%)$ were men and $12(24 \%)$ were women. The average age was $40.1 \pm 11.5$ years. In the control group, nine ( $45 \%)$ were men and $11(55 \%)$ were women; the average age was $43.3 \pm$ 9.8 years. While there was no significant difference between groups with regard to age, a significant difference was found as regards gender. The age and gender distribution of the persons included in the study and their P values are given in Table 1. Laboratory investigations in different study groups are given in Table 1 in which there is statistically significant difference with $\mathrm{P}$-value $<0.05$ between rheumatoid cases and controls with regard to anti-CCP and vitamin D level, with high mean of anti-CCP, and low mean of vitamin D among RA patients.

\section{Vitamin D level ANA titer}

Table 2 illustrates that there is statistically significant difference between rheumatoid cases and controls as regards vitamin D level with $88 \%$ of cases showing insufficient vitamin D versus all controls showing sufficient level.

On the other hand, there is no statistically significance difference with P-value $>0.05$ as regards ANA titer.

\section{Frequencies of SIRT-1 (rs2273773 C $>$ T, rs7895833 A>G, and $r$ 7069102 $\mathrm{C}>\mathrm{G}$ ) gene polymorphisms}

The frequencies of genotypes and alleles in SIRT-1 gene in all groups are shown in Table 3. CC, TC and TT genotype frequencies of rs 2273773 were $36 \%, 38 \%$ and $26 \%$, respectively for the group with RA, and these were $60 \%, 40 \%$ and $0 \%$, respectively for the control group $(\mathrm{P}=0.000)$. While the frequencies of $\mathrm{C}$ and $\mathrm{T}$ alleles of the group with RA were $55 \%$ and $45 \%$, these were $80 \%$ and $20 \%$ for the control group $(\mathrm{P}=$ $0.006)$.

GG, AG and AA genotype frequencies of rs7895833 were $54 \%, 34 \%$ and $12 \%$, respectively for the group with RA, and these were $10 \%, 30 \%$ and $60 \%$ for the control group $(\mathrm{P}=$ 0.000 ). While the frequencies of $\mathrm{G}$ and $\mathrm{A}$ alleles of the group with RA were $71 \%$ and $29 \%$, these were $25 \%$ and $75 \%$ for the control group $(\mathrm{P}<0.001)$.

$\mathrm{GG}, \mathrm{CG}$ and $\mathrm{CC}$ genotype frequencies of rs 7069102 were $62 \%, 26 \%$ and $12 \%$, respectively for the group with RA, and these were $0 \%, 25 \%$ and $75 \%$ for the control group $(\mathrm{P}=0.000)$. The frequencies of $\mathrm{G}$ and $\mathrm{C}$ alleles of the group with RA were $75 \%$ and $25 \%$, and these were $12.5 \%$ and $87.5 \%$ for the control 
Table 3. Distribution of Genotypes and Allelic Frequency Among Patients and Controls

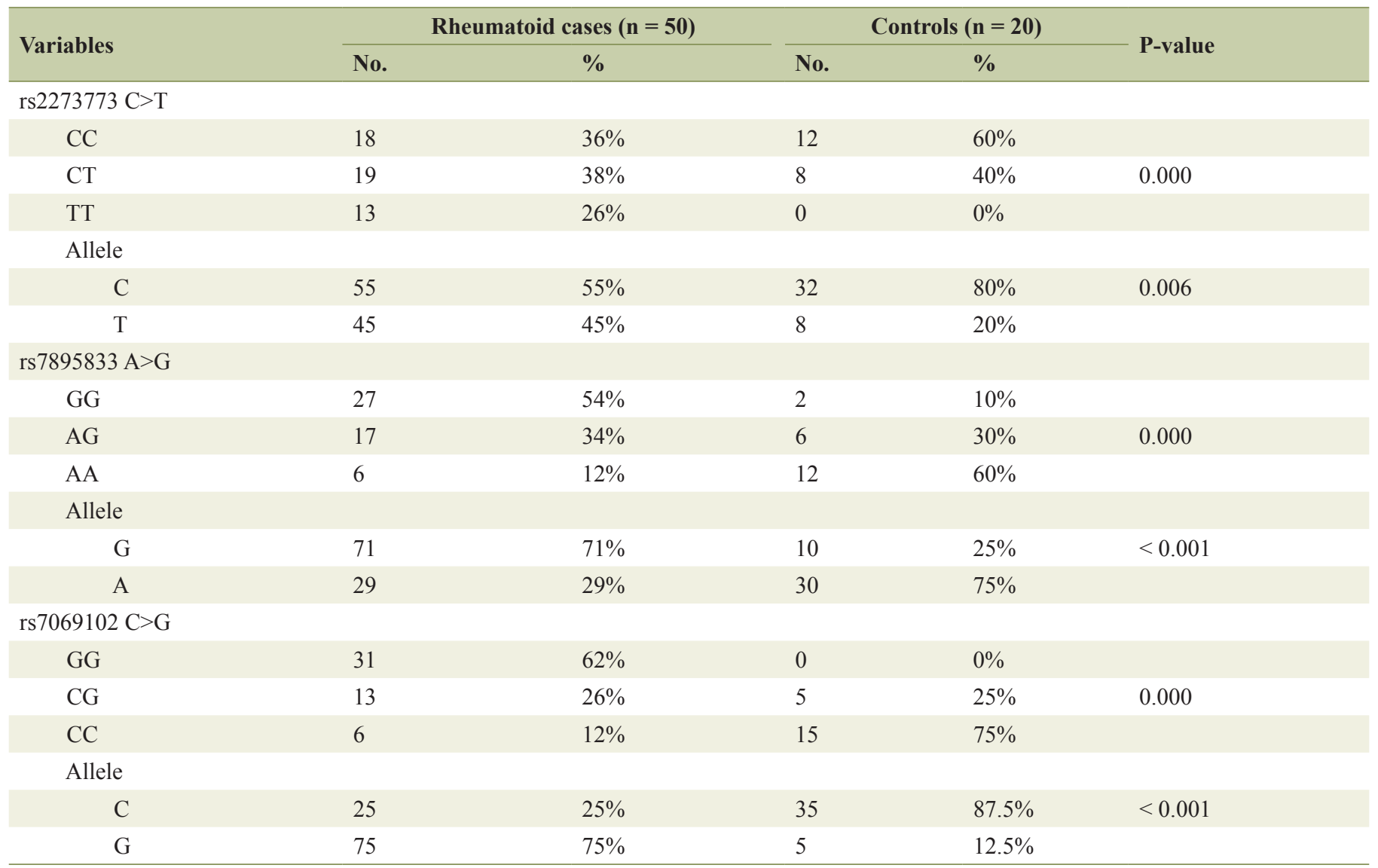

group $(\mathrm{P}<0.001)$.

\section{Relationship between SIRT-1 gene polymorphisms and lev- els of vitamin $D$}

There was no statistically significant difference with P-value $>0.05$ between different genotypes of rs2273773, rs7895833 and rs7069102 as regards vitamin D level (Table 4).

There was no statistically significance difference with P-value $>0.05$ between different genotypes rs2273773, rs7895833, and rs7069102 as regards anti-CCP level (Table 5 ). There is no correlation between vitamin D levels and any other study variables (Table 6).

\section{Discussion}

RA is a chronic inflammatory disease in which there is destruction of joint cartilage and bone. It is characterized by synovial hyperplasia, synovial inflammation, and infiltration of inflammatory immune cells [2].

Our data confirm that vitamin D deficiency is common in our Egyptian patients with RA. Vitamin D levels were found to be insufficient in $88 \%$ of cases and deficient in $6 \%$ of cases.
This result is in agreement with previous reports on patients with RA from other ethnic groups [16, 17].

No relationship was found between $25(\mathrm{OH}) \mathrm{D}$ and any other parameter in the routine investigations. This finding is in

Table 4. Comparisons of Vitamin D in Different SIRT-1 Polymorphisms Among Rheumatoid Patients

\begin{tabular}{cccc}
\hline \multirow{2}{*}{ Variables } & \multicolumn{2}{c}{ Vitamin D } & P-value \\
\cline { 2 - 3 } & Mean & SD & \\
\hline rs2273773 & 17.3 & 9.5 & \\
TT & 16.3 & 4.7 & 0.4 \\
TC & 20.9 & 13.1 & \\
CC & & & \\
rs7895833 & 17.4 & 6.1 & \\
GG & 19.9 & 13.5 & 0.4 \\
AG & 13.9 & 4.6 & \\
AA & & & \\
rs7069102 & 15.9 & 4.5 & \\
GG & 22.1 & 15.7 & 0.2 \\
CG & 16.5 & 5.2 & \\
CC & & & \\
\hline
\end{tabular}


Table 5. Comparisons of Anti-CCP in Different SIRT-1 Polymorphisms Among Rheumatoid Patients

\begin{tabular}{|c|c|c|c|}
\hline \multirow{2}{*}{ Variables } & \multicolumn{2}{|c|}{ Anti-CCP } & \multirow{2}{*}{ P-value } \\
\hline & Mean & SD & \\
\hline \multicolumn{4}{|l|}{ rs2273773 } \\
\hline TT & 59.6 & 23.4 & \\
\hline $\mathrm{TC}$ & 59.1 & 17.4 & 0.6 \\
\hline $\mathrm{CC}$ & 68.5 & 38.3 & \\
\hline \multicolumn{4}{|l|}{ rs7895833 } \\
\hline GG & 67.9 & 29.9 & \\
\hline AG & 58.9 & 18.6 & 0.07 \\
\hline $\mathrm{AA}$ & 41.8 & 13 & \\
\hline \multicolumn{4}{|l|}{ rs7069102 } \\
\hline GG & 58.2 & 23.1 & \\
\hline CG & 71.7 & 39 & 0.3 \\
\hline $\mathrm{CC}$ & 58.2 & 18.7 & \\
\hline
\end{tabular}

agreement with others studies [18].

It was proved that vitamin D deficiency may have a role in the increased levels of proinflammatory cytokines (IL6, IL17, interferon gamma, TNF alpha, etc.) and it plays a very important role in the reduction of inflammation, including suppression of prostaglandin $(\mathrm{PG})$ action, inhibition of p38 stress kinase signaling, and the production of proinflammatory cytokines and inhibition of NF- $\mathrm{\kappa B}$ signaling [3].

Another factor seems to have a role in production of such proinflammatory cytokines which is SIRT-1 gene, which also regulates transcription factors, DNA repair factor $\mathrm{Ku} 70$ and the transcriptional coactivator $\mathrm{p} 300[6,7,9,10]$.

Thereby, SIRT-1 controls a broad range of cellular processes, including cell survival and inflammation [19]. SIRT1 was found to be overexpressed in RA synovial tissues and it directly enhances proinflammatory cytokine production of synovial cells and inhibits apoptosis [20].

Therefore, we planned to investigate the different genotypes and allelic frequency of the SIRT-1 gene in patients with RA. In our study, we analyzed rs7895833, rs7069102 and rs2273773 polymorphisms in the SIRT-1 gene and associated these results with levels of vitamin D and anti-CCP in the studied groups.

A significant difference was found between TT, CT and CC genotypes of rs $2273773 \mathrm{C}>\mathrm{T}$. The incidence of $\mathrm{CC}$ (the wild genotype) was low in patients $(36 \%)$ than in controls $(60 \%)$, while the incidence of TT genotypes (the mutant genotype) in patients was higher $(26 \%)$ than in control $(0 \%)$.

Moreover, we found a significant difference between GG, AG and AA genotypes of rs7895833 A>G, in which the incidence of GG (the mutant genotype) was higher in patients (54\%) than in controls $(10 \%)$, while the incidence of AA genotypes (the wild genotype) in patients was lower (12\%) than in control (60\%). The GG (the mutant genotype) genotype of rs 7069102 $\mathrm{C}>\mathrm{G}$ showed higher frequency in patients $(62 \%)$ than in controls $(0 \%)$ and the CC (the wild genotype) genotype showed low frequency in patients $(12 \%)$ than in controls $(75 \%)$. Thus, the
Table 6. Correlation Between Vitamin D Levels With All Study Variables

\begin{tabular}{|c|c|c|}
\hline \multirow{2}{*}{ Variables } & \multicolumn{2}{|c|}{ Vitamin D } \\
\hline & $\mathbf{r}$ & P-value \\
\hline Age (years) & 0.19 & 0.2 \\
\hline \multicolumn{3}{|l|}{ Complete blood count } \\
\hline $\mathrm{RBCs}$ & 0.15 & 0.3 \\
\hline $\mathrm{Hb}$ & -0.11 & 0.5 \\
\hline TLC & 0.09 & 0.5 \\
\hline PLT & 0.02 & 0.9 \\
\hline \multicolumn{3}{|l|}{ Liver function } \\
\hline ALT & -0.16 & 0.3 \\
\hline AST & 0.04 & 0.8 \\
\hline Total bilirubin & 0.27 & 0.09 \\
\hline Direct bilirubin & 0.25 & 0.08 \\
\hline Albumin & -0.26 & 0.07 \\
\hline \multicolumn{3}{|l|}{ Other routine investigations } \\
\hline Alkaline phosphatase & 0.07 & 0.6 \\
\hline Creatinine & -0.19 & 0.2 \\
\hline $\mathrm{PC}$ & 0.04 & 0.8 \\
\hline CRP & -0.06 & 0.6 \\
\hline INR & 0.14 & 0.3 \\
\hline \multicolumn{3}{|l|}{ Other } \\
\hline Anti-CCP & 0.14 & 0.4 \\
\hline $\mathrm{TSH}$ & -0.16 & 0.3 \\
\hline AFP & -0.19 & 0.2 \\
\hline
\end{tabular}

TT genotype of rs2273773, GG genotypes of rs 7895833 and GG genotype of rs7069102 are high up in patients than in controls.

Therefore, this result may point out the strong relation of TT genotype of rs2273773, GG genotypes of rs7895833 and GG genotype of rs7069102 with RA. Further investigation is necessary to verify its role in remission and activity.

Regarding the allelic frequency of rs2273773, the C allele was dominant in the control group (80\%), and formed about $55 \%$ of the RA group, while the T allele which was seen less frequently in the control group (20\%), formed about $45 \%$ of the rheumatoid arthritis.

On the other hand, the $\mathrm{G}$ alleles of both rs 7895833 and rs7069102 were dominant in the rheumatoid group ( $71 \%$ and $75 \%$, respectively), and were decreasing in the control group ( $25 \%$ and $12.5 \%$, respectively), while the A allele of rs 7895833 and $\mathrm{C}$ allele of rs 7069102 were seen less frequently in the rheumatoid group (29\% and $25 \%$, respectively) and more dominant in the control group ( $75 \%$ and $87.5 \%$ ).

No information on the expression and function of sirtuins in RA was available until very recently. Niederer et al reported the overexpression of SIRT-1 in RA synovial tissue and despite evidence for an anti-inflammatory role of SIRT-1 in animal models of inflammation, they showed that SIRT-1 directly enhances 
proinflammatory cytokine production of synovial cells [20].

SIRT-1 deficient mice display systemic lupus erythematosus-like manifestations, suggesting that SIRT-1 may have a role in autoimmune processes. SIRT-1 targets two major proinflammatory pathways, the NF- $\mathrm{kB}$ and AP-1 pathways, both of which are implicated in the pathogenesis of chronic arthritis. Therefore, SIRT-1 may play a role in the pathogenesis of RA and other forms of arthritis. Research on SIRT-1 in arthritis is still at an early stage. The published data have confirmed that SIRT-1 is overexpressed in RA and is involved in the inflammatory process in the RA synovium.

Macrophages from myeloid SIRT-1 knockout mice showed increased inflammation produced by NF- $\mathrm{\kappa B}$ indicating an anti-inflammatory activity of SIRT-1 [21].

Furthermore, the application of HDAC inhibitors causes genome-wide acetylation of histones, which improve the symptoms in lupus-prone mice [22] and mice induced to develop RA [23], while hyperacetylation of a variety of genetic loci in human SLE is associated with disease severity [24].

Supporting to our results studies in animal models of arthritis have shown useful effects of HDAC inhibitors; Grabiec et al evaluated the effects of different HDAC inhibitors in monocyte-derived macrophages, synovial explants and synovial fluid macrophages of patients with RA [25]. They used NAM, a non-specific inhibitor of sirtuins. Addition of NAM to cultured macrophages of healthy individuals reduced LPS- and TNF- $\alpha$-induced production of IL- 6 and LPS-induced TNF- $\alpha$ production. The findings of Grabiec et al were unexpected, as the data obtained with SIRT-1 deficient or SIRT-1 transgenic mice rather suggested that SIRT-1 has anti-inflammatory effects by inhibiting NF- $\kappa$ B activation. Fernandes et al have used J774 macrophages to study the effect of the sirtuin inhibitors sirtinol and cambinol. They found significantly decreased LPS-induced expression of IL-6, TNF- $\alpha$, and the chemokine Rantes [26].

Studies of resveratrol in synovial cells may be of relevance for understanding the role of SIRTs in RA. Byun et al have shown that treatment of synovial fibroblasts was derived from patients with RA with resveratrol induces apoptosis. This apoptosis was independent of p53 but required activation of caspase 8 [27]. Also, Yang et al explored the effect of resveratrol on the levels of sirtuin 1 (SIRT-1), and they found that resveratrol increases sirtuin 1 expression in peripheral blood mononuclear cells [28].

No previous data associated different genotypes of SIRT-1 polymorphism with RA; we concluded that SIRT-1 polymorphisms may play a role in the development RA. Further studies are needed to explain the role of SIRT-1 in chronic joint inflammation. Moreover, research needs to concentrate on the other members of the sirtuin family. Increased understanding of the impact of sirtuins on immune pathways is needed to be able to design therapeutic strategies targeting sirtuins. In more prospective studies, the SIRT-1 gene expression and mutations should be analyzed with a bigger RA group.

\section{References}

1. Magyari L, Varszegi D, Kovesdi E, Sarlos P, Farago B, Javorhazy A, Sumegi K, et al. Interleukins and interleukin receptors in rheumatoid arthritis: Research, diagnostics and clinical implications. World J Orthop. 2014;5(4):516536.

2. Huber LC, Distler O, Tarner I, Gay RE, Gay S, Pap T. Synovial fibroblasts: key players in rheumatoid arthritis. Rheumatology (Oxford). 2006;45(6):669-675.

3. Guillot X, Semerano L, Saidenberg-Kermanac'h N, Falgarone G, Boissier MC. Vitamin D and inflammation. Joint Bone Spine. 2010;77(6):552-557.

4. Zarrabeitia MT, Valero C, Martin-Escudero JC, Olmos JM, Bolado-Carrancio A, de Sande-Nacarino EL, Rodriguez-Rey JC, et al. Association study of sirtuin 1 polymorphisms with bone mineral density and body mass index. Arch Med Res. 2012;43(5):363-368.

5. Imai S, Johnson FB, Marciniak RA, McVey M, Park PU, Guarente L. Sir2: an NAD-dependent histone deacetylase that connects chromatin silencing, metabolism, and aging. Cold Spring Harb Symp Quant Biol. 2000;65:297302.

6. Brunet A, Sweeney LB, Sturgill JF, Chua KF, Greer PL, Lin Y, Tran H, et al. Stress-dependent regulation of FOXO transcription factors by the SIRT1 deacetylase. Science. 2004;303(5666):2011-2015.

7. Vaziri H, Dessain SK, Ng Eaton E, Imai SI, Frye RA, Pandita TK, Guarente L, et al. hSIR2(SIRT1) functions as an NAD-dependent p53 deacetylase. Cell. 2001;107(2):149159.

8. Yeung F, Hoberg JE, Ramsey CS, Keller MD, Jones DR, Frye RA, Mayo MW. Modulation of NF-kappaB-dependent transcription and cell survival by the SIRT1 deacetylase. EMBO J. 2004;23(12):2369-2380.

9. Cohen HY, Miller C, Bitterman KJ, Wall NR, Hekking B, Kessler B, Howitz KT, et al. Calorie restriction promotes mammalian cell survival by inducing the SIRT1 deacetylase. Science. 2004;305(5682):390-392.

10. Bouras T, Fu M, Sauve AA, Wang F, Quong AA, Perkins ND, Hay RT, et al. SIRT1 deacetylation and repression of p300 involves lysine residues 1020/1024 within the cell cycle regulatory domain 1 . J Biol Chem. 2005;280(11):10264-10276.

11. Simmons GE, Jr., Pruitt WM, Pruitt K. Diverse roles of SIRT1 in cancer biology and lipid metabolism. Int J Mol Sci. 2015;16(1):950-965.

12. Colak Y, Yesil A, Mutlu HH, Caklili OT, Ulasoglu C, Senates E, Takir M, et al. A potential treatment of nonalcoholic fatty liver disease with SIRT1 activators. J Gastrointestin Liver Dis. 2014;23(3):311-319.

13. Pasinetti GM, Bilski AE, Zhao W. Sirtuins as therapeutic targets of ALS. Cell Res. 2013;23(9):1073-1074.

14. Kong L, Wu H, Zhou W, Luo M, Tan Y, Miao L, Cai L. Sirtuin 1: a target for kidney diseases. Mol Med. 2015;21:87-97.

15. Rahman I, Kinnula VL, Gorbunova V, Yao H. SIRT1 as a therapeutic target in inflammaging of the pulmonary disease. Prev Med. 2012;54(Suppl):S20-28.

16. Abourazzak FE, Talbi S, Aradoini N, Berrada K, Keita S, Hazry T. 25-Hydroxy vitamin D and its relationship with clinical and laboratory parameters in patients with rheumatoid arthritis. Clin Rheumatol. 2015;34(2):353-357. 
17. Aguado P, Garces MV, Gonzalez Casaus ML, del Campo MT, Richi P, Coya J, Torrijos A, et al. [High prevalence of vitamin D deficiency in postmenopausal women at a rheumatology office in Madrid. Evaluation of 2 vitamin D prescription regimens]. Med Clin (Barc). 2000;114(9):326330.

18. Feser M, Derber LA, Deane KD, Lezotte DC, Weisman $\mathrm{MH}$, Buckner JH, Mikuls T, et al. Plasma 25, OH vitamin $\mathrm{D}$ concentrations are not associated with rheumatoid arthritis (RA)-related autoantibodies in individuals at elevated risk for RA. J Rheumatol. 2009;36(5):943-946.

19. Donmez G, Guarente L. Aging and disease: connections to sirtuins. Aging Cell. 2010;9(2):285-290.

20. Niederer F, Ospelt C, Brentano F, Hottiger MO, Gay RE, Gay S, Detmar M, et al. SIRT1 overexpression in the rheumatoid arthritis synovium contributes to proinflammatory cytokine production and apoptosis resistance. Ann Rheum Dis. 2011;70(10):1866-1873.

21. Schug TT, Xu Q, Gao H, Peres-da-Silva A, Draper DW, Fessler MB, Purushotham A, et al. Myeloid deletion of SIRT1 induces inflammatory signaling in response to environmental stress. Mol Cell Biol. 2010;30(19):47124721.

22. Mishra N, Reilly CM, Brown DR, Ruiz P, Gilkeson GS. Histone deacetylase inhibitors modulate renal disease in the MRL-lpr/lpr mouse. J Clin Invest. 2003;111(4):539552.

23. Nishida K, Komiyama T, Miyazawa S, Shen ZN, Furumatsu T, Doi H, Yoshida A, et al. Histone deacetylase in- hibitor suppression of autoantibody-mediated arthritis in mice via regulation of $\mathrm{p} 16 \mathrm{INK} 4 \mathrm{a}$ and $\mathrm{p} 21$ (WAF1/Cip1) expression. Arthritis Rheum. 2004;50(10):3365-3376.

24. Nambiar MP, Warke VG, Fisher CU, Tsokos GC. Effect of trichostatin A on human $\mathrm{T}$ cells resembles signaling abnormalities in $\mathrm{T}$ cells of patients with systemic lupus erythematosus: a new mechanism for TCR zeta chain deficiency and abnormal signaling. J Cell Biochem. 2002;85(3):459-469.

25. Grabiec AM, Krausz S, de Jager W, Burakowski T, Groot D, Sanders ME, Prakken BJ, et al. Histone deacetylase inhibitors suppress inflammatory activation of rheumatoid arthritis patient synovial macrophages and tissue. J Immunol. 2010;184(5):2718-2728.

26. Fernandes CA, Fievez L, Neyrinck AM, Delzenne NM, Bureau F, Vanbever R. Sirtuin inhibition attenuates the production of inflammatory cytokines in lipopolysaccharide-stimulated macrophages. Biochem Biophys Res Commun. 2012;420(4):857-861.

27. Byun HS, Song JK, Kim YR, Piao L, Won M, Park KA, Choi BL, et al. Caspase-8 has an essential role in resveratrol-induced apoptosis of rheumatoid fibroblast-like synoviocytes. Rheumatology (Oxford). 2008;47(3):301-308.

28. Yang X, Dong WB, Li QP, Kang L, Lei XP, Zhang LY, Lu $Y Y$, et al. [Resveratrol increases sirtuin 1 expression in peripheral blood mononuclear cells of premature infants and inhibits the oxidative stress induced by hyperoxia in vivo]. Zhongguo Dang Dai Er Ke Za Zhi. 2016;18(1):7277. 